\title{
ANATOMIA DA MADEIRA DE EUGENIA UNIFLORA L. (MYRTACEAE) ${ }^{1}$
}

\author{
SIDINEI RODRIGUES DOS SANTOS ${ }^{2}$ JOSÉ NEWTON CARDOSO MARCHIORI $^{3}$
}

\section{RESUMO}

O presente estudo fornece a descrição anatômica da madeira de Eugenia uniflora L., com base em material do Rio Grande do Sul. A estrutura anatômica reúne características típicas da família Myrtaceae e gênero Eugenia, destacando-se a presença de parênquima apotraqueal em faixas, as fibras de paredes muito espessas e abundantes séries cristalíferas. Foram também observadas diferenças nas características anatômicas quantitativas, com relação a outras espécies do gênero.

Palavras-chave: Eugenia uniflora, pitangueira, anatomia da madeira, Myrtaceae.

\section{ABSTRACT}

[Wood anatomy of Eugenia uniflora L. (Myrtaceae)].

This study provides an anatomical description of Eugenia uniflora wood, based on materials from Rio Grande do Sul state, Brazil. The anatomical structure shows some features that are typical in the Myrtaceae and genus Eugenia, with emphasis on the presence of apotracheal parenchyma in tangential bands, thick-walled fibres and abundant crystalliferous strands. Quantitative differences were also observed, with respect to other species of the same genus.

Key words: Eugenia uniflora, wood anatomy, Myrtaceae.

\section{INTRODUÇÃO}

A família Myrtaceae está representada no Brasil por 24 gêneros e cerca de 1000 espécies (Landrum \& Kawasaki, 1997), um terço das quais pertencentes a Eugenia L. (McVaugh, 1968), gênero que reúne 31 espécies no Rio Grande do Sul (Sobral, 2003).

Eugenia uniflora L. é arvoreta de até $8 \mathrm{~m}$ de altura, nativa na Argentina, Paraguai, Uruguai e Brasil, da Bahia ao Rio Grande do Sul (Legrand \& Klein, 1969). De ampla distribuição neste Estado, a espécie é uma das mais conhecidas da família e ocorre, sobretudo, no es-

\footnotetext{
Os autores agradecem a Geremias Damian Nunes, pelo auxílio nas medições anatômicas. Recebido para publicação em 20/4/2009 e aceito para publicação em 10/6/ 2009.

2 Biólogo, bolsista do $\mathrm{CNPq}$ - Brasil, doutorando do Programa de Pós-Graduação em Engenharia Florestal, Departamento de Ciências Florestais, Universidade Federal de Santa Maria, CEP 97105-900, Santa Maria, RS, Brasil. sthurt.bio@gmail.com

${ }^{3}$ Engenheiro Florestal, Dr., bolsista de Produtividade em Pesquisa do CNPq, Professor Titular do Departamento de Ciências Florestais, Universidade Federal de Santa Maria, Santa Maria, RS, Brasil.
}

trato inferior das florestas, onde chega, por vezes, a compor mais de $20 \%$ dos indivíduos (Klein, 1984; Rotman, 1995).

Popularmente conhecida como pitangueira, fornece madeira pesada, dura, compacta, resistente e de boa durabilidade natural (Lorenzi, 1992), adequada para cabos de ferramentas e peças de pequeno tamanho (Marchiori \& Sobral, 1997).

Para as madeiras do gênero em foco, Record \& Hess (1949) referem: densidade de 0,80 a 1,05 $\mathrm{g} / \mathrm{cm}^{3}$, textura média a fina e grã irregular, com tendência à deformação e rachamento durante secagem.

\section{REVISÃO DE LITERATURA}

Apesar do grande número de representantes e da importância fitofisionômica das Mirtáceas - notadamente do gênero Eugenia - nas floras sul-rio-grandense e brasileira (Klein, 1984; Sobral, 2003), são, ainda, escassas as referências sobre a composição estrutural de suas madeiras.

Em estudo comparativo do lenho de duas espécies da Mata Atlântica (entre elas Eugenia uniflora), Soffiatti \& Angyalossy-Alfonso 
(1999) relacionam: porosidade difusa; vasos exclusivamente solitários; placas de perfuração simples; pontoações intervasculares alternas e guarnecidas; parênquima apotraqueal seriado; raios heterogêneos, estreitos; fibras com pontoações areoladas, de paredes espessas a muito espessas; e traqueídeos vasicêntricos associados aos vasos. A estrutura anatômica, segundo as autoras, exibe pouca variação entre as duas espécies, limitando-se a separação de ambas ao arranjo do parênquima axial e à ocorrência de cristais: Eugenia uniflora, na referida pesquisa, foi distinguida da espécie afim pelo parênquima axial em linhas com 1-3 células de largura, e pelos cristais grandes e abundantes.

Em estudo de Eugenia copacabanensis, Eugenia cuprea e Eugenia macahensis, espécies de remanescentes florestais do Rio de Janeiro, Marques et al. (2007) descrevem estrutura anatômica igualmente homogênea no tocante ao aspecto qualitativo, diferindo as espécies, basicamente, pelo arranjo do parênquima axial e agrupamento de vasos. A importância do parênquima axial para a separação de espécies de Eugenia, aliás, não constitui novidade, sendo destacada por Détienne \& Jacquet (1983, apud Soffiatti \& Angyalossy-Alfonso, 1999), em estudo de várias espécies amazônicas do gênero; com relação a características quantitativas, foram observadas diferenças importantes em todos os aspectos analisados, pelo menos em duas, das três espécies investigadas.

Com relação à flora sul-rio-grandense, Marchiori (1984) e Santos \& Marchiori (2009) referem, para outras espécies do gênero: porosidade difusa; poros solitários; placas de perfuração simples; pontoações intervasculares alternas; parênquima apotraqueal seriado; raios heterogêneos estreitos; e traqueídeos vasicêntricos. Os caracteres diferenciais incluíram: a presença ou ausência de ornamentações em pontoações intervasculares e de espessamentos espiralados em vasos; o arranjo do parênquima axial; a natureza das fibras; e a ocorrência ou não de cristais no parênquima axial.

\section{MATERIAL E MÉTODOS}

O material estudado corresponde a uma amostra de madeira e respectivo material botânico, coletados junto à mata ciliar do rio Ibicuí, no município de São Vicente do Sul (Rio Grande do Sul), incorporados à Xiloteca e Herbário do Departamento de Ciências Florestais da Universidade Federal de Santa Maria (HDCF), sob o número 2396.

Para a descrição da madeira, foram preparadas lâminas de cortes anatômicos e de macerado. Do material lenhoso, foram extraídos três corpos de prova $(3 \times 3 \times 3 \mathrm{~cm})$ da parte mais externa do lenho, próxima ao câmbio, orientados para obtenção de cortes nos planos transversal, longitudinal radial e longitudinal tangencial. Um outro bloco foi também retirado, com vistas à maceração.

No preparo das lâminas de cortes anatômicos, seguiu-se a técnica padrão no Laboratório de Anatomia da Madeira da Universidade Federal do Paraná: as amostras de madeira foram amolecidas por fervura em água e seccionadas em micrótomo de deslizamento, regulado para a obtenção de cortes com espessura nominal de $20 \mu \mathrm{m}$. Os cortes foram tingidos com acridina-vermelha, crisoidina e azulde-astra (Dujardin, 1964), desidratados em série alcoólica-ascendente $(30 \%, 50 \%, 70 \%, 95 \%$ e duas vezes em álcool absoluto), diafanizados em xilol e montados em lâminas permanentes, com "Entellan".

Para as lâminas de macerado, adotou-se o método de Jeffrey (Burger \& Richter, 1991) e coloração da pasta com safranina $1 \%$; a montagem de lâminas seguiu o anteriormente descrito, com a diferença de que as três primeiras etapas foram desenvolvidas sobre papel de filtro.

A descrição microscópica da madeira baseou-se nas recomendações do IAWA Committee (1989). No caso da percentagem dos tecidos, foram realizadas 600 determinações ao acaso, com auxílio de contador de laboratório, conforme proposto por Marchiori (1980). A frequiência de poros foi obtida de forma indireta, 
usando-se um quadrado de área conhecida superposto a fotomicrografias de seção transversal da madeira. As medições foram realizadas em microscópio Carl Zeiss, dotado de ocular com escala graduada, no Laboratório de Anatomia da Madeira da Universidade Federal de Santa Maria. Nas características quantitativas, os números entre parênteses equivalem aos valores mínimos e máximos observados. O valor que acompanha a média é o desvio padrão. As fotomicrografias foram tomadas em microscópio Olympus cx40, equipado com câmera digital Olympus Camedia c3000.

\section{DESCRIÇÃO ANATÔMICA}

Madeira de porosidade difusa (Figura 1A). Anéis de crescimento distintos, delimitados por estreita camada de fibras com diâmetro radial reduzido e paredes fortemente lignificadas.

Vasos muito numerosos a extremamente numerosos $\left(100 \pm 15,9\right.$ poros $\left./ \mathrm{mm}^{2}\right)$, ocupando $18,3 \pm 4,3 \%$ do volume da madeira. Conteúdo de coloração avermelhada, pouco abundante. Poros exclusivamente solitários, de seção oval a circular, muito pequenos $(38 \pm 8,5(20-55)$ $\mu \mathrm{m})$, de paredes espessas $(3,8 \pm 0,8(2,5-5,0)$ $\mu \mathrm{m})$ e sem padrão definido de organização (Figura $1 \mathrm{~A}, \mathrm{~B})$. Elementos vasculares de comprimento médio $(524 \pm 63,6(390-690) \mu \mathrm{m})$, com placas de perfuração simples, oblíquas, por vezes transversais, e apêndices geralmente em ambas as extremidades. Pontoações intervasculares pequenas $(5,0 \pm 0,3(4,1-5,1)$ $\mu \mathrm{m})$, alternas e de forma circular, com abertura em fenda inclusa, não ornamentada. Pontoações raio-vasculares com aréolas distintas, semelhantes às intervasculares, embora menores $(3,6 \pm$ $0,5(3,1-4,1) \mu \mathrm{m})$, principalmente nas margens de raios (Figura 1D). Espessamentos espiralados, ausentes.

Parênquima axial representando 19,2 $\pm 3,9$ $\%$ do volume da madeira, contrastado com relação às fibras, disposto em faixas contínuas e curtos segmentos tangenciais, com 1-3 células de largura (até 5 células, no caso das faixas); também apotraqueal difuso e difuso-em-agregados, em parte. Séries parenquimáticas compostas geralmente de 8 (4-9) células, medindo $433,5 \pm 60,2(337,5-555) \mu \mathrm{m}$ de altura (Figura 1A,B). Séries cristalíferas, abundantes, com até 16 cristais prismáticos solitários, em células normais ou subdivididas do parênquima axial, maiores do que as adjacentes (Figura 1E,F).

Raios muito numerosos $(19 \pm 2,6$ (14-23) raios $/ \mathrm{mm}$ ), ocupando $14,2 \pm 4,4 \%$ do volume da madeira. São heterocelulares, reunindo células procumbentes, na parte multisseriada, e 210 (mais comumente 3-8) fileiras marginais de células eretas, quadradas e, por vezes, células procumbentes mais altas do que as do corpo central (Figura 1C,D). Raios estreitos, com 1-2 (raro 3) células de largura. Raios multisseriados com 8-20, mais comumente 9-15 células de altura, medindo $284,4 \pm 87,3(140-440) \mu \mathrm{m}$; parte multisseriada, geralmente mais curta do que as margens unisseriadas. Raios unisseriados com 2 - 11, mais frequentemente 3-9 células e $187,2 \pm 72,4(60-290) \mu \mathrm{m}$ de altura (Figura $1 \mathrm{E}, \mathrm{F})$. Raios axialmente fusionados, pouco frequentes. Células radiais de paredes disjuntas, presentes. Inclusões minerais, células envolventes, células perfuradas e conteúdos, ausentes.

Fibras de pontoações distintamente areoladas, com aberturas cruzadas, visíveis nas faces radiais e tangenciais da parede. Tecido fibroso representando $48,3 \pm 3,8 \%$ do volume da madeira. Fibras curtas $(878 \pm 141,8(670-1200)$ $\mu \mathrm{m})$, com $15,2 \pm 2,3(12,5-20) \mu \mathrm{m}$ de largura, e de paredes muito espessas $(5,9 \pm 0,95$ (58,7) $\mu \mathrm{m}$ ) (Figura 1B). Fibras septadas, fibras gelatinosas e espessamentos espiralados, ausentes. Traqueídeos vasicêntricos, presentes.

Demais caracteres: Variantes cambiais, tubos laticíferos e taniníferos, canais intercelulares, máculas, células oleíferas ou mucilaginosas e estratificação, ausentes. 

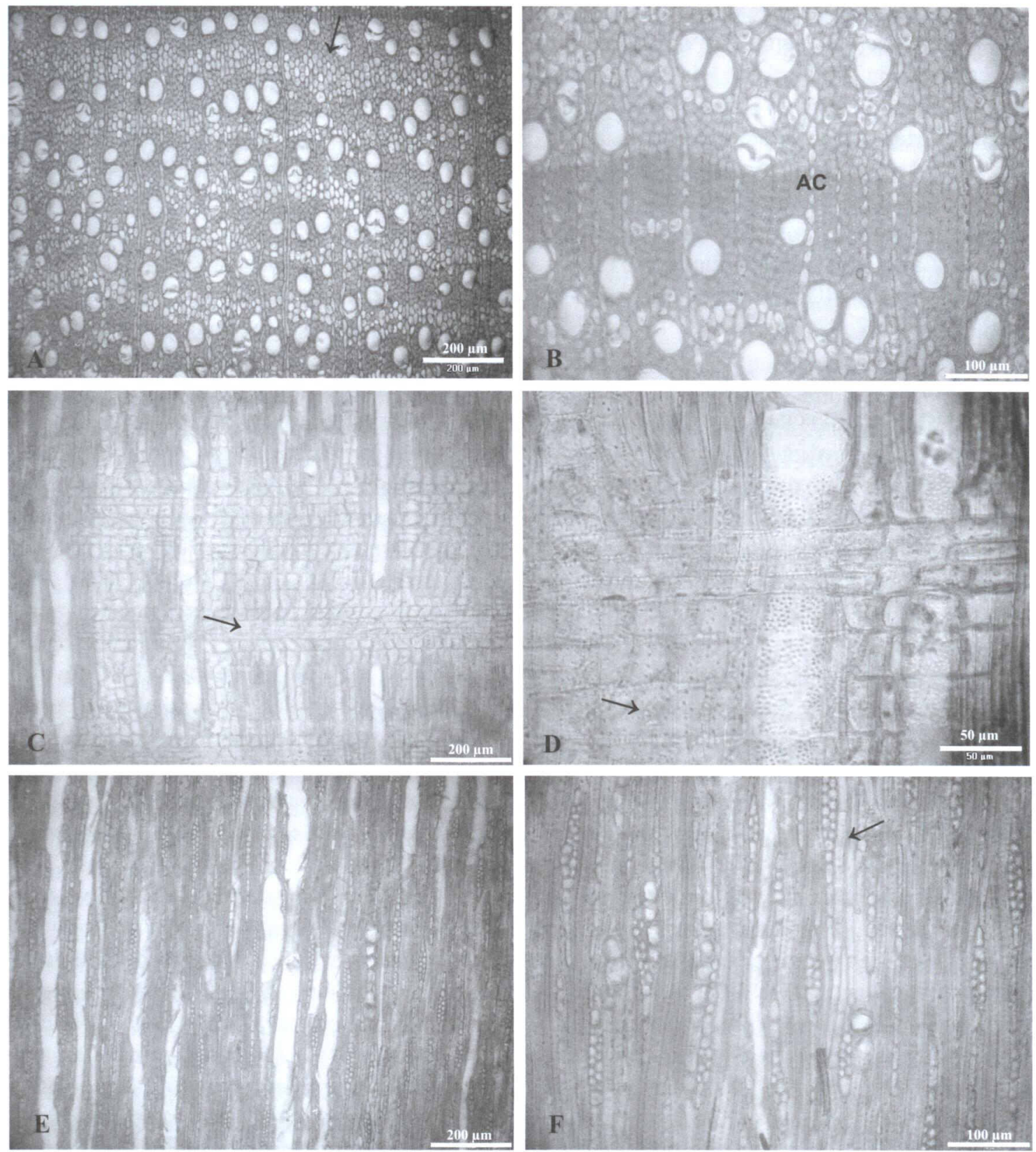

FIGURA 1 - Fotomicrografias da madeira de Eugenia uniflora. A - Seção transversal, mostrando porosidade difusa, poros exclusivamente solitários, e parênquima apotraqueal, em faixas (seta) e difuso-em-agregados. B - Mesma seção, em maior aumento, com destaque para fibras de paredes muito espessas, limite do anel de crescimento (AC), poros de forma oval a circular, e parênquima apotraqueal difuso, difuso-em-agregados e em curtos segmentos tangenciais. C - Aspecto geral de raio heterogêneo, com células procumbentes, no corpo (seta), e margens de células quadradas, eretas e procumbentes, em seção longitudinal radial. D - No detalhe, pontoações raio-vasculares restritas às margens e células radiais de paredes disjuntas (seta). E-Aspecto geral de raios, em vista longitudinal tangencial. F-Mesma seção, em maior aumento, com destaque para raios estreitos, uni e bisseriados, parênquima axial (seta) e séries cristalíferas. 


\section{ANÁLISE DA ESTRUTURAANATÔMICA}

As principais características qualitativas observadas na madeira, tais como vasos exclusivamente solitários, porosidade difusa, placas de perfuração simples, pontoações intervasculares alternas, raios heterogêneos estreitos, fibras com pontoações areoladas e traqueídeos associados a vasos, estão de acordo com o relacionado para as Myrtaceae, por Record \& Hess (1949), Metcalfe \& Chalk (1972) e Dias-Leme et al. (1995).

Além destes aspectos, merecem destaque: a ausência de ornamentações no pontoado intervascular, o parênquima paratraqueal em faixas tangenciais, a presença de séries cristalíferas, e de fibras com paredes muito espessas. Com exceção das pontoações não ornamentadas, as demais características concordam, igualmente, com as possibilidades estruturais referidas na literatura para espécies de Eugenia.

A ausência de ornamentações no pontoado intervascular contrasta com os resultados de Soffiatti \& Angyalossy-Alfonso (1999), que lograram encontrar pontoações ornamentadas nos vasos de Eugenia uniflora. Este fato, aliado a presença generalizada do referido caráter em Myrtaceae, sugere uma natureza excepcional para a sua ocorrência. Estudos adicionais, todavia, serão necessários para definir melhor este ponto, principalmente devido à limitação da microscopia convencional, que não facilita a visualização de ornamentos em pontoações pequenas, caso da espécie em estudo. Cabe salientar que Santos \& Marchiori (2009) também referem pontoações não ornamentadas para os vasos de Eugenia mansoi, contrariando a tendência geral, de acordo com a literatura.

$\mathrm{O}$ arranjo do parênquima axial parece ser uma das características mais úteis à segregação de espécies em Myrtaceae, salvo exceções, como o gênero Myrcia (Dias-Leme, 1995). Os padrões referidos por Détienne \& Jacquet (1983), Soffiatti \& Angyalossy-Alfonso (1999) e Marques et al. (2007), demonstram, de todo modo, a importância do caráter no caso de es- pécies de Eugenia. O parênquima em faixas tangenciais, presentemente observado em Eugenia uniflora, mostra-se suficiente para separar esta espécie de outras do mesmo gênero, descritas por Marchiori (1984) e Santos \& Marchiori (2009), fato que reforça o valor taxonômico do mesmo. Com relação às referências de Soffiatti \& Angyalossy-Alfonso (1999) para a espécie em questão, há que se ressaltar, apenas, diferenças no tocante à largura das faixas, que são mais largas, no presente caso (1-5 células), do que o referido pelas autoras (1-3 células).

Em Eugenia uniflora, chama atenção a ocorrência de fibras com paredes muito espessas. Este aspecto, corroborado por Soffiatti \& Angyalossy-Alfonso (1999), pode ter utilidade na separação da espécie em estudo de outras do mesmo gênero, listadas na bibliografia, possuidoras de fibras com paredes finas até espessas.

A maior parte das características quantitativas concorda, igualmente, com o relacionado por Soffiatti \& Angyalossy-Alfonso (1999), com exceção da frequiência de poros e dos valores mínimos e máximos de certos caracteres anatômicos.

Com relação às espécies nativas de Eugenia anteriormente mencionadas, foram observadas diferenças no tocante à frequiência, diâmetro e espessura de parede de poros, além do comprimento de fibras. A estrutura radial mostra-se bastante homogênea, sob qualquer aspecto, com exceção da freqüência de raios. Com relação à altura dos mesmos, as pequenas diferenças observadas (Eugenia mansoi, por exemplo) podem ser atribuídas, pelo menos em parte, ao predomínio de células eretas nas margens, que, embora sempre heterogêneas, não escondem diferenças sutis na composição. Detalhes desta natureza podem, eventualmente, ser de utilidade na separação de espécies; o uso de caracteres quantitativos para fins taxonômicos, todavia, sempre precisa levar em conta as condições de crescimento das espécies, por sua grande influência sobre a morfologia do xilema secundário, 
conforme demonstrado por Marques et al. (2007), em pesquisa com três espécies de Eugenia.

\section{REFERÊNCIAS BIBLIOGRÁFICAS}

BURGER, L.M., RICHTER, H.G. Anatomia da Madeira. São Paulo: Ed. Nobel, 1991. 154 p.

DIAS-LEME, C.L., GASSON, P., LUGHADA, E.N. Wood anatomy of four Myrtaceae genera in the subtribe Myrciinae from South America. IAWA Bulletin, v. 16, p. 87-95, 1995.

DUJARDIN, E.P. Eine neue Holz-Zellulosenfaerbung. Mikrokosmos, n. 53, p.94, 1964.

IAWA COMMITTEE. IAWA list of microscopic features for hardwood identification. IAWA Bulletin, v.10, n. 3, p. 218-359, 1989.

KLEIN, R.M. Importância sociológica das mirtáceas nas florestas rio-grandenses. Anais do XXXIV Congresso Nacional de Botânica (Porto Alegre), 1984. p. 367-375.

LANDRUM, L.R., KAWASAKI, M.L. The genera of Myrtaceae in Brasil: an illustrated synoptic treatment and identification keys. Brittonia, $\mathrm{n}$. 49, p. 508-536, 1997.

LEGRAND, D., KLEIN, R.M. Mirtáceas. 2. Eugenia L. In: REITZ, P.R. Flora Ilustrada Catarinense. Itajaí: Herbário Barbosa Rodrigues, 1969. p. 45216.

LORENZI, H. Árvores brasileiras: manual de identificação e cultivo de plantas arbóreas nativas do Brasil. Nova Odessa: Editora Plantarum, 1992. 352p.

MARQUES, P.A., ARAUJO, G.U.C., BARROS, C.F., CALLADO, C.H. Anatomia do lenho de três espécies de Eugenia L. (Myrtaceae) de mata e restinga. Revista Brasileira de Biociências, v. 5, p. 801-803, 2007.

MARCHIORI, J.N.C. Estudo anatômico do xilema secundário de algumas espécies dos gêneros Acacia e Mimosa, nativas no Estado do Rio Grande do Sul. 1980. 186f. Dissertação (Mestrado em Engenharia Florestal) - Universidade Federal do Paraná, Curitiba, 1980.

MARCHIORI, J.N.C. Anatomia da madeira de Eugenia involucrata DC. (Myrtaceae). Ciência e Natura, Santa Maria, v. 6, p. 127-136, 1984.

MARCHIORI, J.N.C., SOBRAL, M. Dendrologia das Angiospermas: Myrtales. Santa Maria: Editora UFSM, 1997. 304p.

McVAUGH, R. 1968. The genera of american Myrtaceae, an interim report. Taxon, v. 17, n. 8, p. 354-418, 1968.

METCALFE, C.R., CHALK, L. Anatomy of the Dicotyledons. Oxford: Clarendon Press, 1972. 1500p.

RECORD, S.J., HESS R.W. Timbers of the New World. New Haven: Yale University Press, 1949. 640p.

ROTMAN, A.D. Las especies argentinas del género Eugenia (Myrtaceae). Boletin de la Sociedad Argentina de Botánica, v. 31, n. 1-2, p. 69-93, 1995.

SANTOS, S.R., MARCHIORI, J.N.C. Anatomia do xilema secundário de Eugenia mansoi O. Berg (Myrtaceae). Balduinia, Santa Maria, n. 16, p. 6-12, 2009.

SOBRAL, M. A família Myrtaceae no Rio Grande do Sul. São Leopoldo: Unisinos, 2003. 215p.

SOFFIATTI, P., ALFONSO, V.A. Estudo anatômico comparativo do lenho e da casca de duas espécies de Eugenia L. (Myrtaceae). Revista Brasileira de Botânica, São Paulo, v. 22, n. 2, p. 175184, 1999. 